\title{
Teachers' pedagogical content knowledge and its relation with students' understanding*
}

\author{
RAIMUNDO OLFOS \\ Pontificia Universidad Católica de \\ Valparaíso, Valparaíso, Chile \\ TATIANA GOLDRINE \\ Pontificia Universidad Católica de \\ Valparaíso, Valparaíso, Chile \\ SOLEDAD ESTRELLA \\ Pontificia Universidad Católica de \\ Valparaíso, Valparaíso, Chile
}

\begin{abstract}
We conducted an exploratory study about the relationship between teachers' knowledge and fourth-grade students understanding, in the case of fractions. We studied the content knowledge $(\mathrm{CK})$ and the pedagogical content knowledge (PCK) of 53 teachers and quantified their teaching experience, their mathematical preparation and the socioeconomic and academic background of the schools where the study was conducted. We applied one test at the beginning and one at the end of the school year to 1.532 students, identifying the gains and achievements of each group in the teachers' classrooms. The constructivist-oriented subcomponent of the teachers' CK showed a significant association with student learning, although it is less significant than the association with the teacher's experience. Socioeconomic factors were strongly associated with student achievement, confirming the strong divisions that characterize the chilean education system.
\end{abstract}

\section{KEYWORDS}

education; concepts; instruction; learning; pedagogical content knowledge; knowledge of teaching of content; fractions understanding.

* The development of measurements for this study was supported by a MINEDUC (Chilean Ministry of Education) grant FONIDE-0980, and the research was supported by a CONICYT-FONDECYT-1111009 grant. Funding from the PIA-CONICYT Project CIE-05, Center for Advanced Research in Education, is gratefully acknowledged. The authors thank the Mathematics Institute and the School of Pedagogy of the Pontifical Catholic University of Valparaiso. 


\section{O CONHECIMENTO PEDAGÓGICO DO CONTEÚDO DOS PROFESSORES E SUA RELAÇÃO COM A COMPREENSÃO DOS ALUNOS}

\section{RESUMO}

Foi realizado um estudo exploratório sobre a relação entre o conhecimento de professores e a compreensão de alunos de quarta série, com foco no ensino de frações. Examinamos o conhecimento do conteúdo $(\mathrm{CK})$ e o conhecimento pedagógico do conteúdo (PCK) de 53 professores. Quantificamos a experiência e a preparação matemática desses professores, bem como o nível socioeconômico e acadêmico das escolas onde o estudo foi realizado. Aplicamos um teste para 1.532 alunos, no início e no final do ano escolar, identificando os ganhos e conquistas de cada grupo nas salas de aula dos professores. O subcomponente construtivista orientado do $\mathrm{CK}$ dos professores mostrou uma associação significativa com a aprendizagem do aluno, embora seja menos significativa que a associação com a experiência de ensino do professor. Os fatores socioeconômicos estão fortemente associados com a realização do estudante, atestando as grandes diferenças que caracterizam o sistema educacional chileno.

\section{PALAVRAS-CHAVE}

educação; conceitos; instrução; aprendizagem; conhecimento pedagógico do conteúdo; conhecimento do ensino de conteúdos; compreensão das frações.

\section{EL CONOCIMIENTO PEDAGÓGICO DE LOS PROFESORES SOBRE EL CONTENIDO Y SU RELACIÓN CON LA COMPRENSIÓN DE LOS ALUMNOS}

\section{RESUMEN}

Realizado un estudio exploratorio respecto de la relación entre el conocimiento de los profesores y la comprensión de los alumnos de cuarto grado, enfocado en la enseñanza de las fracciones. Se examinó el conocimiento del contenido (CK) y el conocimiento pedagógico del contenido (PCK) de 53 profesores y se cuantificó su experiencia y preparación matemática, así como el nivel socioeconómico y académico de las escuelas en las que se realizó el estudio. Se aplicó una prueba al inicio y otra al término del año escolar a 1.532 alumnos identificando las ganancias y las conquistas de cada grupo en las clases de los profesores. El subcomponente constructivista orientado del CK por parte de los profesores, mostró una asociación significativa con el aprendizaje del alumno, aunque menos significativa que la asociación con la experiencia del profesor. El factor socioeconómico tuvo una fuerte relación con los logros de los alumnos, dejando en evidencia las fuertes diferencias que caracterizan el sistema educativo en Chile.

\section{PALABRAS CLAVE}

educación; conceptos; instrucción; aprendizaje; conocimiento pedagógico del contenido; conocimiento de la enseñanza del contenido; comprensión de las fracciones. 


\section{INTRODUCTION}

On the american continent and particularly in Chile, grade school students' level of achievement in mathematics is low (Organization for Economic Co-operation and Development [OECD], 2004; Ramírez, 2006; Cariola; Cares; Lagos, 2009). Among the factors associated with achievement and student progress are the characteristics of the educational context and of the teacher: specifically the socioeconomic class of the student's family and the teacher's own knowledge (Akiba; LeTendre; Scribner, 2007; OECD, 2009, 2010; Olfos; Estrella; Del Sol, 2011). Although we may expect that state subsidiary policies guarantee an equitable education, this objective is not achieved in heterogeneous countries or in those with segmented societies, where it is likely that the context of educational inequities affect the relationship between the teacher's knowledge and the student's learning.

The available data regarding teachers' knowledge of content is vague because they refer to different dimensions and concepts of knowledge. Therefore, questions remain about which components of a teacher's knowledge are most closely associated with student achievement and progress and which factors affect this relationship (Hill; Rowan; Ball, 2005; Grossman; McDonald, 2008; Baumert et al., 2010). Our empirical study contributes to understand the relationship between teachers' and students' knowledge, focusing on the educational context.

\section{CHARACTERIZING TEACHERS' KNOWLEDGE}

Some studies show that the mathematical understanding required for quality education is a specific professional knowledge that can be acquired in university training and developed through reflections on teaching practices (Fennema; Romberg, 1999; Grossman, 2008; Morris; Hiebert; Spitzer, 2009).

The past 25 years have shown an international and growing focus on the command of content required for successful teaching (Ma, 1999; Schmidt et al., 2007). These findings have inspired the attempt to characterize an effective teacher's knowledge, noting that the scholarly literature on the subject repeatedly argues that the knowledge base of expert teachers is not only broader than that of inexperienced teachers, but that it is also more connected and integrated (Fennema; Franke, 1992; Darling-Hammond, 2000; Krauss et al., 2008).

Beyond the relevance of strong content knowledge, several authors have argued that being successful mathematics teachers also requires a solid foundation in pedagogical content knowledge: that is, a type of professional knowledge that is used to teach the content of a particular branch of knowledge (Wilson; Shulman; Richert, 1987; Wilson; Floden; Ferrini-Mundy, 2002).

The content knowledge $(\mathrm{CK})$ and pedagogical content knowledge (PCK) are strongly related but distinct entities (Turnuklu; Yesildere, 2007; Buschang, 2008). According to Ball, Lubienski, and Mewborn (2001), the development and selection of tasks, the election of representations and explanations, the facilitation of productive classroom discussions, the interpretation of student responses, the emphasis on student comprehension and the quick and appropriate analysis of student mistakes and difficulties are all underlying elements of PCK. 
An, Kulm, and Wu (2004) assert that between content, curriculum, and teaching, "teaching knowledge" is the basic component of pedagogical content knowledge.

Park and Oliver (2008) state that researchers do not agree on the characterization of the relationship between the various subdomains of teachers' knowledge, although four points are repeatedly and consistently referenced: PC, CK, PCK, and context knowledge.

In 2008, Park and Oliver concluded that PCK is modified by the teacher's reflections on teaching as a whole and that the teacher's understanding of students' misconceptions is the main factor that influences planning, conducting and evaluating teaching in PCK.

Krauss et al. (2008) identified three dimensions of PCK that are important in teaching mathematics: teacher's knowledge of mathematic assignments, teacher's knowledge of students' prior knowledge (difficulties and misconceptions) and teacher's knowledge of representations, analogies, illustrations or useful examples of the mathematical content to be taught.

In their contribution to clarify the knowledge required to teach mathematics, Hill and colleagues (Ball; Hill; Bass, 2005; Hill; Ball; Schilling, 2008) propose three PCK categories: knowledge of content and students (KCS), knowledge of content and teaching (KCT), and knowledge of curriculum. KCS refers to the teacher's familiarity with the students' mathematical thinking, especially with common mistakes they present. Concerning students'learning, these authors make the following distinctions: students' common mistakes and explanations of those mistakes; understanding of students' knowledge and when a student's performance indicates increased appropriation of knowledge; student development sequences (types of problems by age, who learns first, and students' capacities); and common student calculation strategies. Within the KCS framework, the teacher recognizes students' common errors in specific areas, acknowledging that students find certain topics difficult and that some representations may be more or less appropriate for them. KCS has proven to be a robust construct, despite requiring further development, once the conceptualization of the domain and its measurements remain weak.

Hill and colleagues acknowledge that there is little large-scale data on PCK and that the significance of this type of knowledge has to be determined yet. The few empirical studies that venture to discuss the components of teachers' knowledge have been proven prolific in the prediction of students' results (Fennema et al.,1996; Hill; Rowan; Ball, 2005). Nonetheless, the report from the National Mathematics Advisory Panel (2008, p. 37) indicates that

Finally, with the exception of one study that directly measured the mathematical knowledge used in teaching, no studies identified by the Panel probed the dynamic that would examine how elementary and middle school teachers' mathematical knowledge affects instructional quality, students' opportunities to learn, and gains in achievement over time. 
As asserted by Ball, Thames, and Phelps (2008) and by Hill, Ball and Schilling (2008), the PCK construct certainly requires greater theoretical development, as well as greater analytical clarification and empirical support. Their studies have led to a detailed characterization of the mathematical knowledge required to teach mathematics and have established that the teacher's pedagogical content knowledge is a significant predictor of students' achievement in mathematical learning.

\section{OUR MODEL'S COMPONENTS ON TEACHER KNOWLEDGE}

Gathering concepts from the literature that link teacher knowledge with student learning, this study is based on an ad hoc model inspired by the Fundamental Didactic (Brousseau, 1998) to organize teachers' knowledge and explore its relationship with students' understanding. The model is based on the "knowledge-teacher-student" triad that identifies respective knowledge content; KTC, analogous to the knowledge of content and teaching practice (Hill et al., 2008); and the knowledge of students' knowledge, KSK, analogous to the knowledge of content and students' understanding (idem). The first comprises the $\mathrm{CK}$ and the last two would constitute the PCK.

\section{CONTENT KNOWLEDGE}

Our CK conceptualization is rooted in Vergnaud's theory of conceptual fields (1990), in which representations and invariants are inseparable in the process of developing a situational understanding of a concept. Furthermore, we chose specific and in-depth mathematical knowledge linked to the knowledge of teaching. In the CK categories, we consider the conceptual knowledge of the contents and the familiarity with the representations of those subjects.

Conceptual knowledge ( $C c K)$. Includes both specific and general mathematical knowledge. It also includes the specific knowledge on the uses and invariants of the concept of fractions and general knowledge on how they operate or are justified, including testing processes.

Representational knowledge ( $R K$ ). In addition to the specific mathematical knowledge, RK includes the knowledge that relates ideas with different forms of representation. This subcomponent gathers all the specific representations used by the teacher to help to generate student knowledge building and establishing relationships. Some indicators of this are the use of outlines, illustrations, drawings, or the use of materials such as ribbons, paper and cord.

\section{PEDAGOGICAL CONTENT KNOWLEDGE}

Pedagogical content knowledge drawn on Shulman's ideas integrates teaching and learning processes with mathematical knowledge. It is categorized into the KTC and the KSK.

Knowledge of teaching of content (KTC). Teaching knowledge includes the teacher's knowledge about the organization of a school's mathematical curriculum and its sequencing, as well as the constructivist conceptions of mathematics and learning theories proposed by behaviorists or academics, insofar as they guide the 
teacher's decision-making, planning, and actions in the classroom. These actions include the following:

Task organization. The recognition of suitable content sequences and the design of teaching scenarios are considered in the organization of mathematical tasks in a classroom context. The suitable sequences are linked to both school curriculum and analyses or breakdown of students' mathematical tasks. Scenario design depends on the situation; therefore, it includes potentializing the connections between ideas, such as contextualization, analogies, examples and counterexamples, and unifying ideas. Scenario design also considers how a scene is constructed for learning; this refers to how a teacher will emphasize context, use analogies, create cognitive conflicts, or integrate other disciplines, while maintaining the constructivist focus of the learning.

Constructivist orientation. This subcomponent of teaching includes the teacher's conceptions of the meaning of learning mathematics and the learning and teaching of mathematics. According to Pehkonen (2001), conceptions are conscious beliefs that are, at the very least, justified and accepted by the individual.

The teacher's concepts of learning mathematics are associated with her beliefs about how learning occurs and, consequently, about how mathematical content is transformed into teachable content. The following categories emerge from the perspective of the teacher's conceptions of learning theories: behaviorism, cognition, significantism, and socio-constructivism, related respectively to exposing and organizing concept networks, linking different knowledge, and participating and arguing in groups. In this study, we operationalized the first assessment of mathematics as non constructivist and the remainder as constructivist.

Knowledge of students' knowledge. Regarding the teacher's KSK, we link the recognition of knowledge acquired by the students, teacher's awareness of students' conceptualizations, any prior knowledge acquired to face a task successfully and knowledge of the students' difficulties and mistakes about the goal of preempting the repetition of these difficulties and mistakes.

We researched the KSK from two perspectives. The first perspective focused on the identification of the teacher's knowledge of the general knowledge of students' relationships with the mathematical knowledge taught in their schools, particularly regarding fractions, and the second perspective focused on the comparison of the teacher's statements about the students' knowledge with the knowledge of her students.

Problems. Although the proposed construct allows the study of the association between the teacher's knowledge and the students' understanding, it nonetheless requires the assessment of how this association is moderated by factors deriving from the educational context. The educational context is understood as the socioeconomic level of the student's family and the results obtained in national testing at the school at which the instructor works.

Studies conducted in Chile demonstrate that the academic achievement of school-age students is conditioned on factors associated with their socioeconomic level, thus exhibiting a social stratification of the chilean educational system that suggests the pertinence of a stratified sampling (Torche, 2005; Martinez; Guzmán; 
Table 1 - Structures of the studies of the teacher's PCK and CK

\begin{tabular}{lll}
\hline $\begin{array}{l}\text { Content knowledge } \\
\text { (CK) }\end{array}$ & $\begin{array}{l}\text { Conceptual knowledge/CcK: conceptual knowledge of fractions, } \\
\text { including their uses, language, and problem solving. } \\
\text { Representational knowledge/RK: teacher representations of } \\
\text { mathematical objects, both figural and symbolic, regarding fractions. }\end{array}$ \\
\hline & $\begin{array}{l}\text { Knowledge of } \\
\text { teaching of content } \\
\text { (KTC): Knowledge } \\
\text { of the adaptation } \\
\text { of mathematical } \\
\text { knowledge to the } \\
\text { school level. }\end{array}$ & $\begin{array}{l}\text { Task organization/TO: teaching sequences, scene } \\
\text { design for learning, identification of the content } \\
\text { of that level's curriculum, use of context, examples, } \\
\text { and analogies linked to said knowledge. } \\
\text { Constructivist orientation/CO: teacher's } \\
\text { conceptions of mathematics and teacher's } \\
\text { conceptions of constructivist learning (theories). }\end{array}$ \\
\cline { 2 - 3 } $\begin{array}{l}\text { Pedagogical content } \\
\text { knowledge }\end{array}$ & $\begin{array}{l}\text { General KSK/KGSK: teacher's knowledge } \\
\text { regarding conceptualizations or knowledge } \\
\text { acquired, frequent difficulties, possible student } \\
\text { mistakes, and usual strategies, according to } \\
\text { what is indicated in the literature or what the } \\
\text { teacher infers from experience with the topic. } \\
\text { knowledge (KSK): } \\
\text { teacher's knowledge } \\
\text { as it relates to the } \\
\text { student's knowledge. }\end{array}$ & $\begin{array}{l}\text { Teachers own students KSK/KOSK: teacher's } \\
\text { conceptions identified in general KSK but } \\
\text { contrasted with the mistakes, the difficulties, } \\
\text { and the knowledge of her own students. }\end{array}$ \\
&
\end{tabular}

Source: Database search.

Elaborated by the authors.

Cifuentes, 2008; OECD, 2011). Therefore, we assume the context of the school as a variable affecting the associations between the teacher's knowledge and the students'learning.

The questions expressed in this study aim to clarify this relationship by focusing on the concept of fractions acquisition, addressed for the first time in fourth grade under the national school curriculum. What is the teacher's knowledge? How much is this knowledge associated with the conceptualization of fractions by fourth-grade students? Are they significantly associated with disciplinary knowledge, teaching conceptions, and understanding the relationship between student and knowledge, progress, and information acquired in the study of fourth-grade fractions? How does the school's context moderate these associations? In addition, how do these associations affect the teacher's experience and her training in the subject?

\section{METHODS}

\section{VARIABLES}

A non experimental, ex post facto design was established with 10 variables:

a) Two variables from the school context: i) socioeconomic level (SES) of the school in which the mathematics teacher works, according to the stratifi- 
cation of the Ministry of Education, Chile; ii) results in fourth-grade mathematics from students in the schools in which the mathematics teacher is employed, contributed by the education quality measurement system (sistema de medición de la calidad de la educación), SIMCE 09 (Ministry of Education [MINEDUC], 2009).

b) Five variables from the teacher: i) the teacher's knowledge of the fractions and their representations (CK); ii) her knowledge of preconceptions, mistakes, and the difficulties the students will have with the fractions (KSK); iii) her pedagogic conceptions of how to teach fractions and how to organize her teaching (KTC); iv) the teacher's training in hours of mathematics courses; v) years of mathematics teaching experience in the first cycle of grade school teaching, first through fourth grades. This variable had a strong correlation with teachers' age $\left(\mathrm{r}=78^{* *}\right)$. We chose to use teaching experience to reflect better the teachers' suitability.

c) Three student variables: i) achievement or knowledge of the fractions expressed by the student at the end of the fourth grade, according to the contents established in the national curriculum (MINEDUC, 2009); ii) students' development in understanding and using fractions, measured by the difference between a post test and a pretest implemented at the end and at the beginning of the 2010 school year, respectively; and iii) on students' results in a mathematics test, SIMCE 10 (MINEDUC, 2011).

\section{PARTICIPANTS}

The participants were selected randomly and proportionately by strata from approximately $38 \%$ of the 144 schools belonging to the three largest municipalities of the region of Valparaíso, Chile (the answers from one teacher were anonymous; therefore, we have data for 52 schools and 53 teachers). We stipulated the strata were according to socioeconomic status and the mathematics level of achievement of the school in the national evaluation SIMCE 2008 (MINEDUC, 2009). For each stratum, we considered three levels of achievement: significantly above average, average, and below average, as shown in Table 2. There was a replacement of approximately $20 \%$ of the schools with equivalent schools to obtain the participation of the teachers and the consent of the schools' principals. We were unable to replace the total number of establishments with the average SIMCE evaluation results for medium and high socioeconomic status. This resulted in a lower representation of these segments and, therefore, samples with a profile somewhat lower than that of the population, as shown in Table 3.

We randomly chose one grade per school. The teachers participated voluntarily and received remuneration for the hours dedicated to the project. All the teachers taught mathematics courses in at least one fourth-grade class in the selected schools, comprising 1.532 students in this study. 
Table 2 - Number of grades in the sample according to levels in SIMCE and SES

\begin{tabular}{|c|c|c|c|c|}
\hline \multirow{2}{*}{$\begin{array}{c}\text { Distribution of grades } \\
\text { according to SIMCE } 2009\end{array}$} & \multicolumn{3}{|c|}{$\begin{array}{c}\text { Socioeconomic level } \\
\text { (SES) }\end{array}$} & \multirow{2}{*}{$\begin{array}{c}\text { Total } \\
\text { grades }\end{array}$} \\
\hline & High & Medium & Low & \\
\hline Significantly above average & 3 & 3 & 3 & 9 \\
\hline Approximately average & 6 & 8 & 3 & 17 \\
\hline Significantly below average & 8 & 9 & 9 & 26 \\
\hline Total & 17 & 20 & 15 & 52 \\
\hline
\end{tabular}

Source: Database search.

Elaborated by the authors.

Table 3 - Total schools and students involved in the study in relation to the population

\begin{tabular}{lr|r|r}
\hline \multicolumn{1}{c}{ Subjects } & $\begin{array}{c}\text { Number of students } \\
\text { in 4th grade }\end{array}$ & Number of schools & \multicolumn{2}{c}{$\begin{array}{c}\text { Average score in } \\
\text { SIMCE 2010 }\end{array}$} \\
\hline Sample & 1.532 & 52 & 243 \\
\hline Population & 9.883 & 144 & 252 \\
\hline Region of Valparaíso & 22.976 & 410 & 249 \\
\hline Chile & 230.119 & 7.927 & 250 \\
\hline
\end{tabular}

Source: Database search.

Elaborated by the authors.

\section{INSTRUMENTS}

Teacher questionnaire. We designed a questionnaire with 30 questions to measure the teachers' $\mathrm{CK}$ and PCK. We measured the $\mathrm{CK}$ by assessing the conceptual knowledge of the fractions and their representations. The PCK was estimated by assessing two components: on one hand, the conceptions of teaching and knowledge or their organization (KTC), and on the other, the teacher's knowledge of the students' relationship with the knowledge (KSK). Regarding the conception of teaching and its organization (KTC), we assessed two components: the teacher's constructivist orientation toward learning and mathematics and her knowledge of how to organize her teaching. The KSK, was assessed through a generic evaluation perspective, based on the knowledge that the teacher could acquire this component from relevant literature or experience and with a type of evaluation that assesses the teacher's knowledge of her students based on her knowledge of the understanding of her students.

A number of items from other studies were adapted in the construction of the instrument (please see Ball; Hill, 2008; Buschang, 2008). Preliminary tests of the questions were conducted with working teachers. The items' adaptations to the model's categories were determined in agreement between the researchers and the judgments of two external experts. 
Table 4 - Quantity and internal consistency of the items in the teacher's questionnaire by component and subcomponents

\begin{tabular}{|c|c|c|c|c|c|}
\hline \multicolumn{6}{|c|}{$\begin{array}{c}\text { Teacher's knowledge } \\
30(\text { alpha }=.62)\end{array}$} \\
\hline \multirow{2}{*}{\multicolumn{2}{|c|}{$\begin{array}{c}\text { Content knowledge/CK } \\
9(\text { alpha }=.36)\end{array}$}} & \multicolumn{4}{|c|}{ Pedagogical Content Knowledge/PCK } \\
\hline & & \multicolumn{2}{|c|}{$\begin{array}{c}\text { Knowledge of teaching } \\
\text { of content/KTC } \\
12(\text { alpha }=.62)\end{array}$} & \multicolumn{2}{|c|}{$\begin{array}{c}\text { Knowledge of students' } \\
\text { knowledge/KSK } \\
9(\text { alpha }=.17)\end{array}$} \\
\hline $\begin{array}{l}\text { Conceptual } \\
\text { knowledge }\end{array}$ & $\begin{array}{c}\text { Representational } \\
\text { knowledge }\end{array}$ & $\begin{array}{c}\text { Constructivist } \\
\text { orientation }\end{array}$ & $\begin{array}{c}\text { Task } \\
\text { organization } \\
\end{array}$ & $\begin{array}{l}\text { General } \\
\text { KSK }\end{array}$ & $\begin{array}{c}\text { Own students' } \\
\text { KSK }\end{array}$ \\
\hline $\begin{array}{c}6 \\
(\text { alpha }=.38)\end{array}$ & $\begin{array}{c}3 \\
(\mathrm{alpha}=.07)\end{array}$ & $\begin{array}{c}7 \\
(\mathrm{alpha}=.72)\end{array}$ & $\begin{array}{c}5 \\
(\mathrm{alpha}=.11)\end{array}$ & $\left.\begin{array}{c}5 \\
(\text { alpha }=.22\end{array}\right)$ & $\left.\begin{array}{c}4 \\
(\mathrm{alpha}=.39\end{array}\right)$ \\
\hline
\end{tabular}

Source: Database search.

Elaborated by the authors.

Note: $\mathrm{n}=53$.

Taking the exploratory nature of the research study into consideration and addressing the entire spectrum of the components in the model's categories, we diversified the content of the items in the instrument. This affected the validity indexes of the construct by maintaining a broad spectrum of types of knowledge to guarantee the validity of the content, as in Olfos and Zulantay (2007). We employed between three and seven items per component, registering for the CK, KSK, and KTC dimensions Cronbach coefficients of .36,.17, and .62, respectively. The most robust component of these dimensions was the "constructivist orientation", with a Cronbach alpha of .72 which is both the component with the largest number of items and the component that is least dependent on specific disciplinary content variations. The total trustworthiness of the instrument, with 30 items, was .624, as summarized in Table 4.

The questionnaire included a section on the teacher's profile. We considered two primary factors, as follows: i) The teacher's training: number of hours spent in training in mathematics or in its instruction, estimated as 2.400 hours for middle school teachers, 400 hours for grade school teachers, 800 additional hours for general teachers with a specialty in mathematics and additional values between 30 and 120 hours for perfecting courses in the discipline; ii) Years of work experience between the first and the fourth grades in grade school education, considered with the teacher's age. Examples of these items, organized by component, are provided in Appendix A.

Student Questionnaire. The student questionnaire was designed with questions adapted from instruments implemented on a broad scale - SIMCE (MINEDUC, 2008), TIMSS (NCES, 2007), PISA (INECSE, 2005) and SERCE (LLECE, 2009) - and designed to include the previous concepts or knowledge necessary to grasp the concept of fractions, as shown in Table 5. The specific knowledge denotes the acquisition of the understanding of fractions established in the Minimum 
Table 5 - Distribution of the number of items from the student achievement test according to minimum compulsory contents regarding fractions

\begin{tabular}{|c|c|c|c|}
\hline MCC & Item description & $\begin{array}{l}\text { Items on } \\
\text { previous } \\
\text { contents }\end{array}$ & $\begin{array}{c}\text { Items on } \\
\text { understanding } \\
\text { and content } \\
\text { use }\end{array}$ \\
\hline $5 \mathrm{a}$ & Meaning, reading, and writing of simple fractions & 4 & 4 \\
\hline $5 \mathrm{~b}$ & $\begin{array}{l}\text { Use to quantify and compare (parts of an object, parts } \\
\text { of a unit of measurement, and parts of a collection) }\end{array}$ & 6 & 11 \\
\hline $5 \mathrm{c}$ & $\begin{array}{l}\text { Comparison between fractions and } \\
\text { representations on a numerical straight line }\end{array}$ & 0 & 4 \\
\hline 6 & $\begin{array}{l}\text { Values represented by each digit in decimal } \\
\text { numbers between } 0 \text { and } 1 \text { (up to the hundredths) } \\
\text { and their relationships with fractions }\end{array}$ & 1 & 3 \\
\hline
\end{tabular}

Source: Database search.

Elaborated by the authors.

Compulsory Contents (MCC) 5 and 6 of the mathematics curriculum for the fourth grade (MINEDUC, 2009). In this way the validity of the content and the ecology of the instruments are guaranteed for the students.

Two instruments with multiple selection items were used: a test with 13 multiple choice questions applied as a pre and post test to measure the student's progress and a broader test including 33 questions and referred to as the "achievement" test. The difference in points between the post test and the pretest created the "gain" variable. The achievement test considered the post test questions and others that the students could barely answer correctly at the beginning of the year. The achievement test was structured in three 11-item forms whose trustworthiness average was that of $\mathrm{KR}_{20} .76$. The results of the achievement test per class were correlated with those of the SIMCE 2010 test, reaching a value of $r=.68^{* *}$ and contributing to the concurring validity: that is, the validity of the converging character criteria of the instrument. Appendix B presents sample questions from this test.

\section{DATA COLLECTION PROCEDURES}

Teachers answered their questionnaire online, which offered privacy, trust and freedom to answer according to the teacher's availability and work schedule. The time spent answering these questions varied between 25 and 85 minutes.

The tests were administered to the students in groups in their classrooms during school. The test forms were distributed randomly in a manner proportionate to the number of students in the classroom. The pretest was given during the first three months of the year and the post test and the achievement test were given in the last month of academic year 2010, one week after the national evaluation SIMCE 2010 was conducted. 


\section{DATA ANALYSIS PROCEDURES}

The correlation analyses established associations between the students' achievement and their gains in knowledge with the teacher's background data and the characteristics of the school environment. We tabulated the results of the student tests, obtaining the number of correct answers in relation to the number of questions per form. To avoid the weighting of the level of difficulty of each form, we averaged the number of correct answers per form and per class, obtaining a percentage of correct answers per class.

In addition to these correlations, we explored linear regression models and studied the influences of teacher characteristics, considering the socioeconomic level and the school's results in the SIMCE 2009 evaluation.

\section{RESULTS}

\section{TEACHER KNOWLEDGE AND STUDENT KNOWLEDGE}

In the assessment of $\mathrm{CK}$, the teachers answered an average of $37 \%$ of the questions on the conceptualization of fractions and $57 \%$ of the answers on their representations correctly. This total is equal to $43 \%$ of the correct answers in the area of CK. For instance, item 20 referred to the teacher's understanding of the concept of a fraction and was answered correctly by 10 of 53 teachers, while item 18, referring to the teacher's knowledge of the representation of the unit and the parts of a fraction, was answered correctly by 14 teachers (please see Appendix A).

In the area of teaching knowledge, the teachers answered $59 \%$ of the answers regarding their conceptions from a constructivist perspective and answered correctly $50 \%$ of the questions on the teaching organization. This is equivalent to a total of 56\% correct answers regarding KTC. For example, 41 and 43 of the teachers, respectively answered items 4 and 5, which measure the teacher's knowledge of the national curriculum guidelines for teaching organization, correctly. Items 8 and 9, which inquire about the teacher's tendency to select teaching methods and situations from a constructivist perspective, were answered correctly by 33 and 37 of the teachers respectively (please see Appendix A).

Regarding the teachers' understanding of the students' relationship with knowledge, the teachers answered 32\% of the questions assessing general KSK and $33 \%$ of the KSK answers considering their students correctly. This result is equivalent to $33 \%$ correct answers in the area of KSK. For example, 22 and 23 teachers respectively answered correctly items 27 and $25 \mathrm{~b}$, which measure the teachers' knowledge of frequent mistakes made by students when learning about fractions. Twenty-four teachers answered correctly item $24 \mathrm{~b}$, which asks the teachers to anticipate their students' possible difficulties with fractions (please see Appendix A).

The participating students answered an average of $31 \%$ of the pretest questions and $38 \%$ of the post test questions correctly, presenting a gain of $7 \%$. In 
Table 6 - Correlations between teacher and student variables

\begin{tabular}{|c|c|c|c|c|c|c|c|c|c|c|}
\hline \multirow[b]{2}{*}{ (number of classes) } & \multicolumn{7}{|c|}{ Teacher Variables } & \multicolumn{3}{|c|}{$\begin{array}{c}\text { Class Variables } \\
\text { (Student) }\end{array}$} \\
\hline & $\begin{array}{l}\text { MMP } \\
((52)\end{array}$ & $\begin{array}{l}\text { TTE } \\
((52)\end{array}$ & $\begin{array}{l}\text { CCK } \\
((52)\end{array}$ & $\begin{array}{l}\text { PPCK } \\
((52)\end{array}$ & $\begin{array}{l}\text { KKTC } \\
((52)\end{array}$ & $\begin{array}{l}\mathrm{CCO} \\
((52)\end{array}$ & $\begin{array}{c}\text { KKSK } \\
((52)\end{array}$ & $\begin{array}{l}\text { SSIMCE } \\
((52)\end{array}$ & $\begin{array}{l}\text { Ach } \\
((50)\end{array}$ & $\begin{array}{c}\text { GGain } \\
((40)\end{array}$ \\
\hline $\begin{array}{l}\text { Mathematical } \\
\text { Preparation/MP }\end{array}$ & 1 & $-.24^{*}$ & $.26^{*}$ & .17 & .21 & .21 & .02 & -.11 & $-.25^{*}$ & .06 \\
\hline $\begin{array}{l}\text { Teaching } \\
\text { Experience/TE }\end{array}$ & & 1 & -.07 & .12 & -.06 & -.07 & .17 & .04 & $.39^{* *}$ & .24 \\
\hline CK & & & 1 & $.29^{*}$ & .02 & -.02 & $.38^{* *}$ & .05 &. .04 & -.14 \\
\hline PCK & & & & 1 & $.92^{* *}$ & $.82^{* *}$ & $.65^{* *}$ & .18 & $.29^{*}$ & $.32 *$ \\
\hline KTC & & & & & 1 & $.90^{* *}$ & $.31^{*}$ & .10 & .20 & $.33^{*}$ \\
\hline $\begin{array}{l}\text { Constructivist } \\
\text { Orientation/CO }\end{array}$ & & & & & & 1 & $.24^{*}$ & .09 & .21 & $.26^{*}$ \\
\hline KSK & & & & & & & 1 & $.26^{*}$ & $.32^{*}$ & .13 \\
\hline SIMCE 10 & & & & & & & & 1 & $.68^{* *}$ & .02 \\
\hline Achievement/Ach & & & & & & & & & .11 & .04 \\
\hline Gain & & & & & & & & & & 1 \\
\hline
\end{tabular}

Note: Spearman correlation: 1 tail.

${ }^{*} p<.05 .{ }^{* *} p<.01$.

Source: Database search.

Elaborated by the authors.

addition, the students reached a score of $36 \%$ in the achievement test. For instance, item B1 was the easiest question in the pretest and was answered correctly by $50 \%$ of the students; it was also the easiest in the post test and was answered correctly by $69 \%$ of the students. Item B2 had 18\% correct answers in the pretest and $29 \%$ in the post test. Item C4 had 14\% correct answers in the pretest and 29\% in the post test (items in Appendix B and C).

\section{ASSOCIATIONS BETWEEN THE TEACHER'S KNOWLEDGE AND HER STUDENTS' KNOWLEDGE}

Table 6 presents the relationships between the teacher variables and the student variables. the associations between the teacher's CK and her students' knowledge are the following: the teacher's $\mathrm{CK}$ and the students' gain do not exhibit a significant association to $5 \%, \mathrm{r}=-.14$. Likewise, the teacher's $\mathrm{CK}$ and the students' achievement do not demonstrate a significant association to $5 \%, r=.04$.

The associations between the teacher's PCK and the students' knowledge are the following: 
Table 7 - Association of the teacher variables and the school context with gain and achievement ${ }^{1}$

\begin{tabular}{ccccccccc}
\hline & \multicolumn{2}{c}{$\begin{array}{c}\text { Total classes } \\
(\mathrm{n}=52)\end{array}$} & \multicolumn{2}{c}{ High $(\mathrm{n}=18)$} & Medium $(\mathrm{n}=21)$ & \multicolumn{2}{c}{ Low $(\mathrm{n}=13)$} \\
\cline { 2 - 9 } & gain & $\begin{array}{c}\text { achieve- } \\
\text { ment }\end{array}$ & gain & $\begin{array}{c}\text { achieve- } \\
\text { ment }\end{array}$ & gain & $\begin{array}{c}\text { achieve- } \\
\text { ment }\end{array}$ & gain & $\begin{array}{c}\text { achieve- } \\
\text { ment }\end{array}$ \\
\cline { 2 - 9 } & .24 & $.39^{* *}$ & .20 & $.43^{* *}$ & .34 & .38 & -.27 & $.52^{*}$ \\
\hline Exper. & $.32^{*}$ & $.39^{*}$ & $.40^{*}$ & .18 & .19 & .37 & .05 & .21 \\
\hline PCK & $.33^{*}$ & $.20^{*}$ & .37 & .14 & .24 & $.39^{*}$ & -.07 & -.01 \\
\hline KTC & .13 & $.32^{*}$ & .33 & .20 & .02 & .21 & .23 & $.59^{*}$ \\
\hline KSK & .14 & .04 & .16 & .02 & -.26 & .08 & .25 & -.02 \\
\hline CK & .20 & $.68^{* *}$ & -.06 & $.78^{* *}$ & $.47^{*}$ & $.46^{*}$ & -.25 & .21 \\
\hline SIMCE 10 & .20 & & & & & &
\end{tabular}

Source: Database search.

Elaborated by the authors.

a) The teacher's PCK and the students' gain show a significant correlation to $5 \%, r=.32$. When we disaggregated the components of PCK, we verified that the KTC component associated with the student's gain, $\mathrm{r}=.33^{*}$, and the "constructivist orientation" subcomponent is associated with the gain, $\mathrm{r}=.26^{*}$. However, the KSK component of the PCK does not achieve a significant association to $5 \%$ and a gain of $\mathrm{r}=.13$.

b) The teacher's PCK and the students' achievement show a significant association to $5 \%, r=.29^{*}$. When we disaggregated the PCK, the association of student achievement with the KSK is $r=.32$, significant to $5 \%$, while the association of the achievement with $\mathrm{KTC}$ is $\mathrm{r}=.20$, nonsignificant to $5 \%$.

\section{INFLUENCE OF THE SCHOOL CONTEXT ON THE ASSOCIATION BETWEEN THE}

\section{TEACHER'S KNOWLEDGE AND THE STUDENTS' KNOWLEDGE}

The variables of the school's context used in the sampling of this study refer to the socioeconomic level (SES) of the school in which the teacher works and to the results from the mathematics test, fourth grade, SIMCE 2009, obtained by the school in the year preceding this study.

According to the sample presented in Table 7, when we analyzed the relationship between the teacher's knowledge, $\mathrm{CK}$ and $\mathrm{PCK}$, and the student's knowledge, disaggregated by socioeconomic level, we discovered significant associations that provide possible explanations for the preceding results.

In the high SES, the PCK, but not the CK, significantly affects the gain. Neither the CK nor the PCK reaches significant associations for achievement.

1 We assumed normal bivariant variables. However, we also analyzed the polyserial correlations, leading to results similar to those described here (Spearman rho, 1 tail). 
In the medium SES, neither the PCK nor the CK significantly affects either achievement or gain. Neither the $\mathrm{CK}$ nor the $\mathrm{PCK}$ reaches significant associations for achievement. In a disaggregation of the PCK, only KTC is associated significantly to $5 \%$ with the achievement, $r=.39^{*}$.

In the low socioeconomic status category, neither the PCK nor the CK significantly affects achievement or gain. However, when disaggregating the PCK, the KSK is associated with achievement, $\mathrm{r}=.59^{*}$.

However, when contrasting the variable of SIMCE 10 with students' gain and achievement, we observed that the SIMCE 10 strongly correlates with the achievement, $\mathrm{r}=.68^{* *}$. When disaggregated for SES, we discover that in the medium SES, achievement is associated with the SIMCE $10, r=.46^{*}$. With greater strength, the SIMCE 10 is also associated with the high SES, $r=.78^{* *}$. The association was not significant in the low SES. In contrast, although the SIMCE 10 did not show a significant association with gain, upon disaggregation for SES, we verified that in the medium SES the association was significant, $r=.47^{*}$.

\section{INFLUENCE OF TEACHER VARIABLES IN THE ASSOCIATION BETWEEN THE}

\section{TEACHER'S KNOWLEDGE AND THE STUDENTS' UNDERSTANDING}

This study considered the teacher's number of hours of training in mathematics courses and years of first through fourth-grade teaching experience in mathematics as variables that could be associated with their CK and PCK and the level of understanding reached by the students.

A strong association was obtained between the teacher's experience and student achievement, $r=.39^{* *}$. The association between the teacher's experience and the students' gain was not significant. Furthermore, experience did not show a significant association with CK, nor with PCK or their components KTC and KSK. When disaggregating for SES, we verified that the association between the teacher's teaching experience and student achievement is always positive, with its significance being $r=.52^{*}$ in the low SES and $r=.43^{* *}$ in the high SES. As expected, experience is associated with age, $r=.78^{* *}$.

The teacher's years of mathematical preparation did not exhibit a significant association with the students' gain. In addition, it is noteworthy that the teacher's years of education showed a significant negative association with student achievement, $\mathrm{r}=-.25^{*}$. It should also be noted that the mathematical preparation correlated negatively, $\mathrm{r}=-.59^{* *}$, with the students' results in the SIMCE 10. When disaggregating for SES, we verified that the association between the teacher's mathematical preparation and student achievement was always negative, significant in the medium SES, $r=-.40^{*}$, and highly significant in the high SES, $r=-.62^{* *}$.

\section{PERCENTAGE VALUES OF THE TEACHER VARIABLES IN RELATION TO THE SCHOOL CONTEXT}

Although on average, the teachers showed little knowledge in both $\mathrm{CK}$ and PCK, at $43 \%$ and $45 \%$, respectively, differences were observed according to the SES 
Table 8 - Background of training, experience and age of the teachers and their knowledge

\begin{tabular}{lcccccccccccc}
\hline & \multicolumn{3}{c}{$\begin{array}{c}\text { Teacher } \\
\text { Background }\end{array}$} & \multicolumn{3}{c}{ CK } & \multicolumn{3}{c}{ KTC } & \multicolumn{3}{c}{ KSK } \\
\hline SES & MP & TE & Age & CK & CcK & RK & KTC & CO & TO & KSK & General & Own \\
\hline All & 603 & 14.5 & 44,2 & $43 \%$ & $37 \%$ & $57 \%$ & $56 \%$ & $59 \%$ & $50 \%$ & $33 \%$ & $32 \%$ & $33 \%$ \\
\hline High SES & 664 & 12.7 & 43 & $46 \%$ & $40 \%$ & $60 \%$ & $56 \%$ & $60 \%$ & $50 \%$ & $33 \%$ & $36 \%$ & $30 \%$ \\
\hline Med SES & 514 & 17.4 & 49.3 & $42 \%$ & $38 \%$ & $50 \%$ & $57 \%$ & $61 \%$ & $50 \%$ & $29 \%$ & $26 \%$ & $33 \%$ \\
\hline Low SES & 657 & 12.7 & 37.9 & $42 \%$ & $32 \%$ & $63 \%$ & $54 \%$ & $56 \%$ & $52 \%$ & $37 \%$ & $36 \%$ & $38 \%$ \\
\hline
\end{tabular}

Source: Database search.

Elaborated by the authors.

in the schools in which they worked. Table 8 presents some of these differences in the disaggregation of the teacher variables according to SES.

The teachers with the highest number of hours of mathematical preparation and fewest years of teaching experience are in the high SES. Interestingly, despite the facts that teaching experience is associated with student achievement and mathematical preparation is associated negatively with achievement, the teachers with high SES have the highest percentage of correct answers in CK - like their students - and a PCK, both in KTC as in KSK, that is equal to the average. It is important to note that the high-SES teachers are not known for having a greater percentage of correct constructivist-orientation answers regarding their knowledge of the understanding and knowledge of their own students.

The teachers who work in medium-SES schools have more years of teaching experience and fewer years of mathematical preparation. They also present lower CK and KSK averages, and their average PCK is on the KTC average.

The group of teachers in the medium-SES category obtained the lowest percentage of correct answers in the representation items and the lowest percentage of correct answers on the acknowledgement of difficulties and frequent mistakes, or general KSK. However, this group of teachers has a percentage equal to the average in regards to their knowledge of their own students.

The low-SES teachers are young teachers on average, but they have above-average training. Their CK and KTC are low, but they are exceptional in their above-average knowledge of students' knowledge, regarding both their knowledge of students' challenges and frequent mistakes and the difficulties of and errors made by the students in their specific classes.

Table 8 furthers the hypothesis that teachers with the most teaching experience in mathematics have had fewer hours of mathematical preparation. This is verified in Table 6 , which demonstrates a negative association, $r=-.24^{*}$, between teaching experience and mathematical preparation. 
Table 9 - Gain from the pretest to the post test and student achievement, disaggregated by socioeconomic level - SIMCE 2010 averages

\begin{tabular}{l|r|r|r|r|r}
\hline & \multicolumn{1}{r}{ SIMCE 2010 } & \multicolumn{1}{c}{ Pretest } & \multicolumn{1}{c}{ Post test } & Gain & Achievement \\
\hline High SES & 265 & $36 \%$ & $43 \%$ & $8 \%$ & $43 \%$ \\
\hline Medium SES & 242 & $31 \%$ & $38 \%$ & $6 \%$ & $35 \%$ \\
\hline Low SES & 219 & $23 \%$ & $31 \%$ & $5 \%$ & $29 \%$ \\
\hline Total & 243 & $31 \%$ & $38 \%$ & $7 \%$ & $36 \%$ \\
\hline
\end{tabular}

Source: Database search.

Elaborated by the authors

Note: The differences in the calculations follow the variations in the number of subjects that took the pretest, the post test and the achievement tests together.

Table 10 - Percentage of the achievement by SIMCE 2009 level and SES in the schools

\begin{tabular}{l|r|r|r}
\hline \multirow{2}{*}{ SES } & \multicolumn{3}{c}{ SIMCE 2009 } \\
\cline { 2 - 5 } & \multicolumn{2}{c}{ Low Level } & \multicolumn{2}{c}{ Medium Level } & High Level \\
\hline High & $18 \%$ & $24 \%$ & $36 \%$ \\
\hline Medium & $18 \%$ & $20 \%$ & $18 \%$ \\
\hline Low & $14 \%$ & $15 \%$ & $16 \%$ \\
\hline
\end{tabular}

Source: Database search.

Elaborated by the authors.

\section{STUDENT RESULTS}

As shown in Table 9, the students' gains during the year in relation to their knowledge of fractions were small, an average of $7 \%$, inferred from the difference between the post test and the pretest. The levels of understanding at the beginning of the year were approximately $31 \%$, and the year closed at approximately $38 \%$. We can observe that the best levels were reached in the high SES with $43 \%$ and that the students of low SES reach the starting level of the medium-SES group, which reaches at least one-third of the level achieved by the high-SES students. We also observed that the higher the SES the greater the gain over the course of the year. The results from the fraction tests coincide with the SIMCE results that the national average is slightly higher than the medium-SES level.

As presented in Table 10, student achievement is associated with the school's context, which is, to the SES and the SIMCE 2009 scores, correspond to the stratified selection criteria of the sample.

\section{REGRESSION STUDY}

The research showed a significant relationship between the studied variables ( $\mathrm{p}<.001$ ), in which the teacher PCK was able to explain 13\% of the variability in 
student achievement. The PCK is able to explain that the $\mathrm{CK}$, reaching a level of explanation of $17 \%(\mathrm{p}=.01)$, is part of the variability when the PCK and CK variables act jointly. When integrating other variables into the model, the study demonstrated that the socioeconomic level that characterizes the students by their school and teacher experiences behaved as better predictors, and that, in short, these factors explain 49\% ( $\mathrm{p}<.001$ ) of the student achievement (please see Appendix D).

The consistency of these results is also guaranteed by the normality of the distributions of the residues and the apparent nonexistence of a bias, as visualized in the graphs of Appendix D.

\section{DISCUSSION}

The results show that teachers who teach fourth-grade math have little in-depth knowledge of fractions and their instruction. Likewise, the results indicate that the teachers' number of hours of mathematical preparation did not contribute to either the gain or achievement of their students. The study shows the need to delve deeper and reorient the research study to focus on the factors that affect the student gain and achievement in mathematics between the first and fourth grades in Chile.

The study considered a school sample whose average performance in national tests was below the national average - please see Table 3 - and was limited to the topic of teaching conceptualization in mathematics. The study excluded other forms of learning that are usually taught with greater success by chilean teachers, such as rules or algorithms. Further, the study focused on fractions, which is acknowledged as a difficult topic by both teachers and publications showing results from national tests.

We discuss the results from two perspectives. The first focuses on the findings and the second approaches the topic of the validity of the study, from the perspectives of both construct and content. Lastly, we analyze the projections for future studies.

\section{FINDINGS}

Teacher knowledge plus understanding associated with student learning. The study shows that unlike the CK, the teacher's PCK is significantly associated with student gain and achievement, although not at a high intensity. In addition, when examining the components of PCK, we observed that the teaching component, KTC, was significantly associated with achievement and, even more significantly, with students' gain; the other PCK component, KSK, only shows a significant association with student achievement.

Upon considering these findings in depth, we verified that the teacher's "constructivist orientation" subcomponent is significantly associated with student gain, which is a matter of importance for two reasons. First, the analysis of the validity of the construct used in this study demonstrated the consistency of such measurements. Second, it contributes to clarifying one of the PCK components, a 
topic of current research relevance in mathematical education (Ball; Thames; Phelps, 2008; Hill; Ball; Schilling, 2008).

Other teacher factors associated with student learning. The teaching experience proved to be more strongly associated with student achievement than the PCK. On the other hand, the PCK is more associated with student gain than the gain is with the teacher's teaching experience. In any of these cases, experience, like the $\mathrm{PCK}$, is more associated with the CK to the student's achievement and gain. The teaching experience has no significant association with the CK or the PCK, which leads us to assume that both the teaching experience and the PCK are factors that are promoted to enhance the student's gain and achievement.

The teacher's number of hours of mathematical preparation is not associated with the students' gain and, curiously, is negatively associated with achievement. This result could be explained by the fact that mathematical preparation is also negatively associated with teaching experience. That is, young teachers, or those who have chosen to achieve greater mathematical preparation than experience, present lower achievement. This explains how CK, which is significantly associated with mathematical preparation, has no association with achievement.

This background leads to a reconsideration of the orientation of initial and continuous teacher training. The study showed that younger teachers have greater mathematical preparation; however, this does not affect the students' gain and achievement. In addition, teaching experience did not correlate with CK or with PCK. This can presumably be explained by the tendency of initial and continuous training of teachers to discipline and teach by rote and out of context, thus preventing a harmonious integration between mathematical knowledge and mathematical instruction and between theory and practice. This may explain why more training does not result in greater and more efficient mathematical knowledge of teaching and adds to a traditional school culture with an academic orientation.

In this regard, the existing literature (Fennema, Romberg, 1999; Baumert et al., 2010) indicates that the teacher's PCK configuration implies training in a specific area strengthened by a reflexive practice that leads to an effective practice. According to the data collected in this study, this would require an emphasis on initial and continuous training in Chile.

The effects of the school context. The stratification of the sample based on SES is relevant, given that Chile appears to be the country with the greatest social inequality of all of the countries in the OECD (2011). It was expected that SES would be the greatest predictor of school achievement. The contribution of this study in relation to SES is the quantification of its effect on the relationships between PCK and CK and student gain and achievement.

This study shows how the SES, a variable in the school context, is even more closely associated with the student's achievement than teaching experience, PCK, $\mathrm{CK}$, and the teacher's mathematical preparation. However, the high correlation between the SIMCE 1- and student achievement, $r=.68^{* *}$, provides evidence for the consistency of this measurement of achievement, revealing the high associations between SES and other measurements associated with mathematics education in 
Chile. We verified that achievement is highly associated with the school's SES and that the SES is a more stable variable than the teachers' characteristics.

At the predictive level, the PCK can explain 13\% of the variability in the achievement; together with the CK, it can explain $17 \%$ of that variability. When we consider SES as the school context and the teacher's teaching experience, we achieve a predictive model that explains $49 \%$ of the variability in achievement.

As mentioned above, the student gain is slight, with an average of 7\%, when comparing the post test with the pretest. The best levels were reached in the high SES, with $43 \%$ in the post test. This result shows that learning the concept of fractions in the fourth grade is difficult and that the educational system has not been able to overcome this challenge. These data coincide with the perception in Chile based on the results of national testing that measure the quality of the educational system.

The fraction test results coincide with the SIMCE's results that the national average is slightly higher than the medium socioeconomic level. This demonstrates that factors of the school's context are strongly relevant to the student's learning achievement and reveals that the sampling was pertinent and well implemented. As previously mentioned, low-SES students reach the level in their post tests at which the medium-SES group began in their pretest, and the latter achieve less than one-third of the level reached by the high-SES students. The greater the SES is, the greater the obtained gain. These conclusions are consistent with the background of the inequities of the national educational system and the pertinence of this study.

\section{CONCERNING THE VALIDITY OF THE MODEL'S COMPONENTS}

\section{AND ITS PROJECTIONS}

We built the teacher's instrument under an $a d$ hoc CK and PCK model, including some items from other studies (see for instance Ball and Hill, 2008; Buschang, 2008). These items cover a broad spectrum of knowledge identified as pertinent within the framework of the revision of the literature associated with teacher's knowledge of fractions and teaching fractions. Within the exploratory context of the study, we developed a heterogeneous instrument that is sensitive to criteria for content validation that allow the incipient model components to be questioned and acknowledge the possible limitations of the validity of the construct. The instrument reached an internal consistency level acceptable for an exploratory study (alpha $=.62 ; n=30$ ), with one of its components being deemed sufficiently robust. The low internal consistency indexes for CK (alpha=.36; $n=9)$ and for KSK $(\mathrm{alpha}=.17 ; \mathrm{n}=9)$ show that the instrument gathers isolated knowledge evidence that apparently fails to conform to a one-dimensional category for the declared models, with the exception of the KTC component, whose internal consistency is acceptable (alpha $=.62 ; n=12)$. The results show that the PCK component went further toward explaining the $\mathrm{CK}$ and that the internal component of PCK, KTC, was the most robust in terms of its internal consistency $(\mathrm{alpha}=.62 ; \mathrm{n}=12)$ and explained the most in terms of its association with student gain, specifically in the items referring to constructivist orientation. The other PCK component, KSK, 
appeared not to be robust (alpha $=.17 ; \mathrm{n}=9$ ), although it contributed significantly to explaining student achievement.

The instrument built to measure student achievement showed a trustworthiness index of $\mathrm{KR}_{20}=.76$. The high association between achievement and SIMCE 10, $r=.68^{* *}$, contributed to the concurrent validity, adopted as the converging validity criterion of the instrument.

The analysis of the results of this application of the instruments leads to the verification of a partial association between the knowledge constructs of the teacher and the student, particularly in the dimension in which the instruments reached an acceptable consistency. In addition, beyond the model's limitations and the limitations of the instrument and the exploratory nature of the design, the associations showed significance; the regression model granted an explanatory value to the construct and to the initial suppositions "CK-savoir, KTC-teacher; KSK-student" that emerged from the basic instruction. In turn, this granted ecologic validity to the model.

Critical Revision of the CK Component. The measurement of the CK provided evidence of the slight in-depth knowledge that teachers express on average regarding fractions, with barely $43 \%$ of correct answers. These items present a high difficulty in the selected sample, demonstrating that teachers reflect very little on the mathematical content: that is, there is a lack of in-depth knowledge of the content.

The items that measured the CK covered two categories, one of conceptual knowledge with six items $(\mathrm{alpha}=.38)$ and another of representational knowledge with six items $(\mathrm{alpha}=.07)$. These items cover a heterogeneous spectrum of knowledge associated with the knowledge of fractions in the school curriculum. The items referred to, for example, both the availability and the efficient management of strategies to evaluate relationships between fractions, such as the in-depth knowledge of the representations and language linked to the use of fractions. These are a variety of types of knowledge, which, when present in the items as subcomponents, were not treated with equivalent items that would demonstrate the internal consistency of the measurements. The development of tests with a greater number of subcomponent items that require a teacher of fractions and general content to achieve effective teaching of the school curriculum is still pending.

Although it is not robust, the measurement of CK used in this study shows that mathematical knowledge is the foundation of a teacher's knowledge of teaching. For example, this study demonstrated that the group of students with the worst results belonged to the low SES and had teachers whose average CK was $10 \%$ lower than that of the high-SES teachers, despite similar levels of mathematical preparation and teaching experience. One explanation for the low influence of the teacher's CK on student achievement and gain could be provided by the high level of difficulty and the high specificity of the mathematical content measured in the teacher assessment items. This specificity and difficulty may affect the constitution of a unique factor and, therefore, the contributions of these heterogeneous elements may lead to indexes that show a low association between their items.

Critical Revision of the KSK Component. The results demonstrated that the KSK, own-students-KSK, and general-KSK components are heterogeneous. 
Table 11 - Internal Consistency of Eventual CK Components

\begin{tabular}{l|l|r}
\hline $\begin{array}{l}\text { Number } \\
\text { of Items }\end{array}$ & \multicolumn{1}{c}{ Eventual Components } & alpha \\
\hline 6 & CK conceptual knowledge & .38 \\
9 & CK conceptual knowledge + CK representational knowledge & .35 \\
14 & CK conceptual knowledge + CK representational knowledge + general KSK & .50 \\
\hline
\end{tabular}

Source: Database search.

Elaborated by the authors.

Beyond reaching a low internal consistency, in the context of the low number of items involved, alpha $=.22$ for the five items of the general-KSK, and alpha $=.39$ for the four items of the own-students-KSK, the fusion of items into a single category becomes unsustainable; the results show that the two subcomponents refer to different types of knowledge, alpha $=.17$. The general-KSK is a type of knowledge closer to the KSC component of PCK studied by Hill, Ball, and Schilling (2008) than to the direction of the context of the students in each class group. In fact, correlating the general-KSK with CK improves the internal consistency, as shown in Table 11.

In addition, the measurements of the KSK lead to low results. The teachers demonstrated little knowledge of their students, with only 33\% providing correct answers.

Despite the measured characteristics of KSK described above, the group of items used to express the presence of this supposed factor in teaching reached a significant association with student achievement and the SIMCE10 results, providing evidence for the importance of the ideas these items represent.

The four items used to measure the teachers' own-students-KSK were not required to demonstrate the internal consistency that was proposed for the remainder of the study items because their validation is obtained by contrasting each teacher's answers with those of her students. This subcomponent of the teacher's knowledge was predictive of the students' achievement, favoring low-SES teachers, whose predictions were usually of the students' failure. Therefore, this subcomponent needs to be improved in a future formulation of the items.

Critical Revision of the KTC Component. As explained in the presentation of the methodology and experimental results, the KTC component is the most robust at alpha $=.62$, and it has the greatest predictive value. The subcomponents of the model presented a priori, as in the KSK, are further objects of discussion. By itself, the constructivist orientation component with seven items is more consistent, at alpha $=.72$, than the complete component with twelve items. The task organization subcomponent would then constitute an independent factor. Furthermore, with five items, it reaches an extremely low internal consistency of alpha $=.11$, testifying to the diversity of the knowledge involved and the inherent complexity of these measurements.

The constructivist orientation is linked to the beliefs or conceptions of the teacher, while the organization of the teaching refers to another type of knowledge. 
On one hand, some elements of task organization refer to the teacher's knowledge of the school curriculum: that is, of the norms that sequence the contents treated at the different educational levels. Other items refer to scenario design and the use of contextualization, examples, and analogies in the teaching of fractions. Therefore, these are heterogeneous types of knowledge, some of which need to be developed by the teacher in effective teaching, while others are previously established in curricular documents. The identification and selection of the types of knowledge that comprise the task organization component are pending while new items are crafted and their levels of difficulty are studied.

\section{CONTRIBUTIONS}

This study validates the possibility of verifying significant relations between teachers' knowledge and students' understanding by means of instruments applied to real and representative contexts, which demonstrates the study's high degree of ecologic validity.

Based on the preceding paragraph, this research contributes to the study of the CK and PCK of the teacher because it characterizes the weight of the construct in comparison with teachers' backgrounds, such as experience and training, and because one of its components, constructivist orientation, is required in a valid and significant manner.

This study, which explores an exploratory model of CK and PCK in an original manner, is distinctive because it focuses on the conceptualization of fractions, a topic of strong interest in mathematical education.

The depth of this study permitted the analysis of the relationships between student and teacher knowledge within the framework of the complexity of a segmented educational system, identifying variations in this relationship according to social divisions, an issue that is difficult to approach and, therefore, seldom made explicit.

The findings of the study are consistent with studies conducted by Hill, Rowan, and Ball (2005); Grossman and McDonald (2008); and Baumert et al. (2010), among others, who acknowledge the difficulty of measuring PCK. Following An, Kulm, and Wu, (2004), this study identified the KTC as a main factor, distancing itself from the statement made by Park and Oliver (2008), who propose the KSK as the main factor.

\section{REFERENCES}

Akiba, Motoko; Letendre, Gerald; Scribner, Jay. Teacher quality, opportunity gap, and national achievement in 46 countries. Educational Researcher, Wahington, DC: Sage Publications, v. 36, n. 7, p. 369-387, 2007.

An, Shuhua; Kulm, Gerald; Wu, Zhonghe. The pedagogical content knowledge of middle school, mathematics teachers in China and the U.S. Journal of Mathematics Teacher Education, Netherlands: Springer, n. 7, p. 145-172, 2004.

Ball, Deborah; Lubienski, Sarah; Mewborn, Denise. Research on teaching mathematics: the unsolved problem of teachers' mathematical knowledge. In: 
Richardson, V. (Ed.). Handbook of research on teaching. 4th ed. Washington, DC: American Educational Research Association, 2001. p. 433-456.

Ball, Deborah; Hill, Heather; Bass, Hyman. Knowing mathematics for teaching: who knows math well enough to teach third grade and how can we decide? American Educator, Washington, DC: American Federation of Teachers, v. 29, n. 1, p. 14-17, p. 20-22, p. 43-46, 2005.

BALl, Deborah; Hill, Heather. Mathematical knowledge for teaching (MKT) measures. Mathematics released items 2008. Ann Arbor: University of Michigan, 2008.

Ball, Deborah; Thames, Mark; Phelps, Geoffrey. Content knowledge for teaching: What makes it special? Journal of Teacher Education, Washington DC: Sage Publications, v. 59, n. 5, p. 389-407, 2008.

BAumert, Jürgen et al. Teachers' mathematical knowledge, cognitive activation in the classroom, and student progress. American Educational Research Journal, Washington DC: Sage Publications, v. 47, n. 1, p. 133-180, 2010.

B rousseau, Guy. Théorie des situations didactiques. Paris: Pensée Sauvage, 1998.

Buschang, Rebecca. Validating measures of math teacher knowledge. California Educational Research Association Annual Meeting CERA, Rancho Mirage, CA, 2008.

Cariola, Leonor; Cares, Gabriela; Lagos, Ema įQué nos dice PISA sobre la educación de los jóvenes en Chile? Santiago, Chile: Ministerio de Educación, Unidad de Curriculum y Evaluación, SIMCE, 2009.

Darling-Hammond, Linda. Reforming teacher preparation and licensing: debating the evidence. Teachers College Record, New York: Columbia University, v. 102, n. 1, p. 28-56, 2000.

Fennema, E Elizabeth et al. A longitudinal study of learning to use children's thinking in mathematics instruction. Journal for Research in Mathematics Education, Reston: NCTM, v. 27, n. 4, p. 403-434, 1996.

Fennema, Elizabeth; Franke, Megan. Teachers' knowledge and its impact. In: Grouws, D. A. (Ed.). Handbook of research on mathematics teaching and learning. New York: MacMillan, 1992. p. 147-164.

Fennema, Elizabeth; Romberg, Thomas (Eds.). Mathematics classrooms that promote understanding. Mahwah, NJ: Lawrence Erlbaum Associates, 1999.

Grossman, Pam. Responding to our critics: from crisis to opportunity in research on teacher education. Journal of Teacher Education, Washington DC: Sage Publications, v. 59, n. 1, p. 10-23, 2008.

Grossman, Pam; Mcdonald, Morva. Back to the future: directions for research in teaching and teacher education. American Educational Research Journal, Washington DC: Sage Publications, v. 45, n. 1, p. 184-205, 2008.

Hill, Heather; Rowan, Brian; Ball, Deborah. Effects of teachers' mathematical knowledge for teaching on student achievement. American Educational Research Journal, Washington DC: Sage Publications, v. 42, n. 2, p. 371-406, 2005.

Hill, Heather; BAll, Deborah; Schilling, Stephen. Unpacking pedagogical content knowledge, conceptualizing and measuring teachers' topic specific knowledge of 
students. Journal for Research in Mathematics Education, Reston: NCTM, v. 39, n. 4, p. 327-400, 2008.

Instituto Nacional de Evaluación y Calidad del Sistema Educativo [INECSE]. PISA 2003. Pruebas de matemáticas y de solución de problemas. Instituto Nacional de Evaluación y Calidad del Sistema Educativo. Madrid: España, 2005.

Krauss, Stefan; Baumert, Jürgen; Blum, Werner. Secondary mathematics teachers' pedagogical content knowledge and content knowledge: validation of the COACTIV constructs. The International Journal on Mathematics Education, Netherlands: Springer, v. 40, n. 5, p. 873-892, 2008.

Krauss, Stefan et al. Pedagogical content knowledge and content knowledge of secondary mathematics teachers. Journal of Educational Psychology, Washington, DC: American Psychological Association, v. 100, n. 3, p. 716-725, 2008.

Laboratorio Latinoamericano de Evaluación de la Calidad de la Educación [LLECE]. Segundo Estudio Regional Comparativo y Explicativo [SERCE]. Aportes para la enseñanza de la Matemática. Santiago: UNESCO, 2009.

MA, Liping. Knowing and teaching elementary mathematics. Teachers' understanding of fundamental mathematics in China and the United States. Mahwah, NJ: Erlbaum, 1999.

Martínez, Pablo; Guzman, Jenny Mancilla; Cifuentes, Gonzalo. Reconfiguration of the social educational map as a territorial manifestation of the chilean neoliberal society. Scripta Nova Revista Electronic de Geografía y Ciencias Sociales, Barcelona: Universidad de Barcelona, v. 12, n. 270, 2008.

Ministerio de Educación [MinedUC]. SiMCE. Niveles de logro 4o básico para matemática. Unidad de Currículum y Evaluación Ministerio de Educación. Chile, 2009.

. Propuesta Ajuste Curricular. Objetivos fundamentales y contenidos mínimos obligatorios. Matemática. Junio. Chile, 2009.

. SIMCE. Niveles de logro $4^{\circ}$ básico para matemática. Unidad de Currículum y Evaluación, 2011.

Morris, Anne; Hiebert, James; Spitzer, Sandy. Mathematical knowledge for teaching in planning and evaluating instruction: what can pre-service teachers learn? Journal for Research in Mathematics Education, Reston: NCTM, v. 4, n. 5, p. 491-529, 2009.

National Center for Education Statistics [NCES]. Student questionnaire. Grade 4th TIMSS USA. Department of Education. Washington, DC, 2007.

National Mathematics Advisory Panel. Foundations for success: the final report of the National Mathematics Advisory Panel. Department of Education. Washington, DC, 2008.

Organization for Economic Co-Operation and Development [OECD]. Revisión de políticas nacionales de educación: Chile. OECD, Paris y Ministerio de Educación de Chile, 2004.

Creating effective teaching and learning enviroments: first results from TALIS. Paris: OECD, 2009.

. Sintesis estudio económico de Chile. 2010. 
Society at a glance 2011 OECD social indicators. 2011.

Olfos, Raimundo; Estrella, Soledad; Del Sol, Claudia. ¡Sí, es posible!: un caso de enseñanza de la matemática. In: Campos, J.; Montecinos, C.; González, A. (Eds.). Mejoramiento escolar en acción. Valparaíso: CIAE-PUCV, 2011. p. 81-102.

Olfos, Raimundo; Zulantay, Hildaura. Reliability and validity of authentic assessment in a web based course. Educational Technology \& Society, Canada: International Forum of Educational Technology \& Society, v. 10, n. 4, p. 156-173, 2007.

Park, Soonhye; Oliver, Steve. Revisiting the conceptualization of pedagogical content knowledge (PCK): PCK as a conceptual tool to understand teachers as professionals. Research in Science Education, Netherlands: Springer, v. 38, n. 3, p. 261-284, 2008.

Penkonen, Erkki. A hidden regulating factor in mathematics classrooms: mathematics related beliefs. In: Ahtee, M.; Björkevist, O.; Pehronen, E.; Vatanen, V. (Eds.). Research on mathematics and science education. East Lansing: Michigan State University, Institute for Educational Research, University of Jyväskylä, 2001. p. 11-35.

Pinto, Jesús. Conocimiento didáctico del contenido sobre la representación de datos estadísticos: estudios de casos con profesores de estadística en carreras de psicologí y educación. Dissertation (Doctoral) - Universidad de Salamanca, Spaña, 2010.

Ramírez, María. Understanding the low mathematics achievement of chilean students: a cross-national analysis using TIMSS data. International Journal of Educational Research, Netherlands: Elsevier, v. 45, p. 102-116, 2006.

Sснміdт, William et al. The preparation gap: teacher education for middle school mathematics in six countries - mathematics teaching in the 21st Century (MT21). East Lansing, MI: MSU, 2007.

Torche, Florencia. Privatization reform and inequality of educational opportunity: the case of Chile. Sociology of Education, Washington, DC: ublications, 78, n. 4, p. 316$-343,2005$.

Turnuklu, Elif; Yesildere, Sivel. The pedagogical content knowledge in mathematics: preservice primary math teachers' perspectives. IUMPS: The Journal, Texas: Texas Tech University, v. 1, p. 1-13, 2007.

Vergnaud, Gerard. La théorie des champs conceptuels. Récherches en Didactique des Mathématiques, Grenoble: La pensée sauvage v. 10, n. 23, p. 133-170, 1990.

Wilson, Suzanne; Floden, Robert; Ferrini-Mundy, Joan. Teacher preparation research: an insider's view from the outside. Journal of Teacher Education, Washington DC: Sage publications, v. 53, n. 3, p. 190-204, 2002.

Shulman, Lee; Richert, Anna. "150 different ways" of knowing: representations of knowledge in teaching. In: Calderhead, J. (Ed.). Exploring teachers' thinking. New York: Taylor and Francis, 1987. p. 104-124. 


\section{APPENDIX A}

\section{Examples of Items for the Teacher by Subcomponent with the Correct Alternative **** marks the correct alternative}

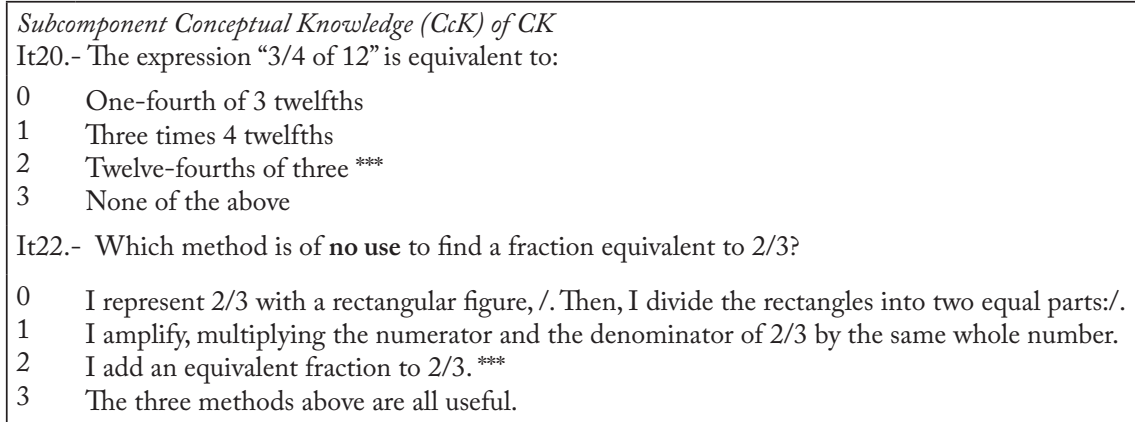

It18.- Teacher Jiménez considers it is important to vary the unit when she teaches fractions. One day she used one hundred pesos and then twelve eggs as the unit. Now she uses a drawing of two pizzas. What fraction of the pizzas is she illustrating below?

$\begin{array}{lllll}0 & 5 / 4 & \text { b. } 5 / 3 & \text { c. } 5 / 8^{* * *} & \text { d. } 1 / 4\end{array}$

Subcomponent Task Organization (TO) of KTC-PCK

Item 4 measures the organization of a sequence and item 5 measures the identification of curriculum content. It 4 - What sequence of contents would you include in your fraction unit plan?

0 Represent the fraction concept; introduce the sum of the fractions with equal and distinct denominators and exercises.

1 Define and incorporate the language of fractions, present the sum with an equal denominator, and solve application problems.

2 Represent situations from daily life with fractions, formalize these, represent additive situations with fractions with equal denominators, formalize and practice.

3 Represent quotidian situations with fractions, formalize them, compare fractions, represent additive situations with fractions with the same denominator, formalize and practice. ${ }^{* * * *}$

It5.- In addition to the notion of part-whole, what idea(s) about the fractions $1 / 2,1 / 3,1 / 4,1 / 8,3 / 4$, and $1 / 10$, is (are) included in the Curricular Adjustment of the 4th grade?

I The representation of these fractions in the number line

II The comparison of these fractions among themselves

III The employment of these fractions to quantify part of a collection of objects

$0 \quad$ Only I and II

1 Only I and III

2 Only II and III

3 All: I, II and III *** 
(continuação...)

Subcomponent Constructivist Orientation (CO) of KTC-PCK

It 8.- Several students from the 4 th grade $B$ do not know that $1 / 4 \mathrm{~kg}$ of flour is half of $1 / 2 \mathrm{~kg}$ of flour.

What strategy would the teacher recommend?

0 Show the children that $1 / 4+1 / 4$ is $2 / 4$; that is, $1 / 2$.

1 Ask the children to represent or make a sketch with the fractions and compare them. ${ }^{* * *}$

2 Give the children homework with several representation exercises with the fractions $1 / 4$ and 1/2.

3 Show the children a representation of these fractions on the number line.

0 Which of the following teaching methods do you prefer to use in the classroom?

$0 \quad$ Exemplify and then propose group application work

1 Explain the ideas in detail and provide examples and exercises

2 Present situations to explore, share, and discuss ${ }^{* * * *}$

3 Express only what is essential and provide many exercises

Subcomponent General KSK-PCK

Item 27 measures the knowledge of the teacher on the strategies of the students, item 256 measures the knowledge on her student's mistakes

It27.- The teacher asked the students to shade " $1 / 4$ " of the circles /

Who did the exercise correctly?!

0 Only Maria's answer is correct.

The answer by Trinidad is also correct, though more intuitive and laborious. ${ }^{* * *}$

The answer by Trinidad is more elaborate, efficient, mathematical and economic than Maria's.

I'm not sure.

It25b.- Faced with the question "What fraction of the figure is shaded?" several students answered 5/4.

This could be due to

0 /Confusing the numerator with the denominator

1 Confusing the denominator with the complement ${ }^{* * *}$

2 Making a mistake in the calculations

3 Not counting the shaded cells to determine the denominator ***

Subcomponent Own Students KSK-PCK

It $24 \mathrm{~b}$ measures the teacher's knowledge of the understanding acquired by her students

It24b Upon finishing teaching about fractions, what proportion of the class do you estimate will answer the question correctly?

There are 600 balls in a box, and 1/4 of these balls are red. How many red balls are there in the box?
I) 600 balls
II) 2400 balls
III) 150 balls
IV) 200 balls

0 More than $66 \%$ of the students will answer correctly

1 Between $33 \%$ and $66 \%$ will answer correctly

2 Less than $33 \%$ will respond correctly

3 I do not know

*** The correct answer depends on the real situation of each classroom, based on the students' answers to each teacher.

Items that relate students' knowledge to the teacher's PCK

Student test. Form A item 7:

There are 600 balls in a box, and $1 / 3$ of these balls are red. How many red balls are in the box?
a) 600 balls
b) 1800 balls
c) 200 balls
d) 300 balls 


\section{APPENDIX B}

\section{Examples of Pretest Questions for Students}

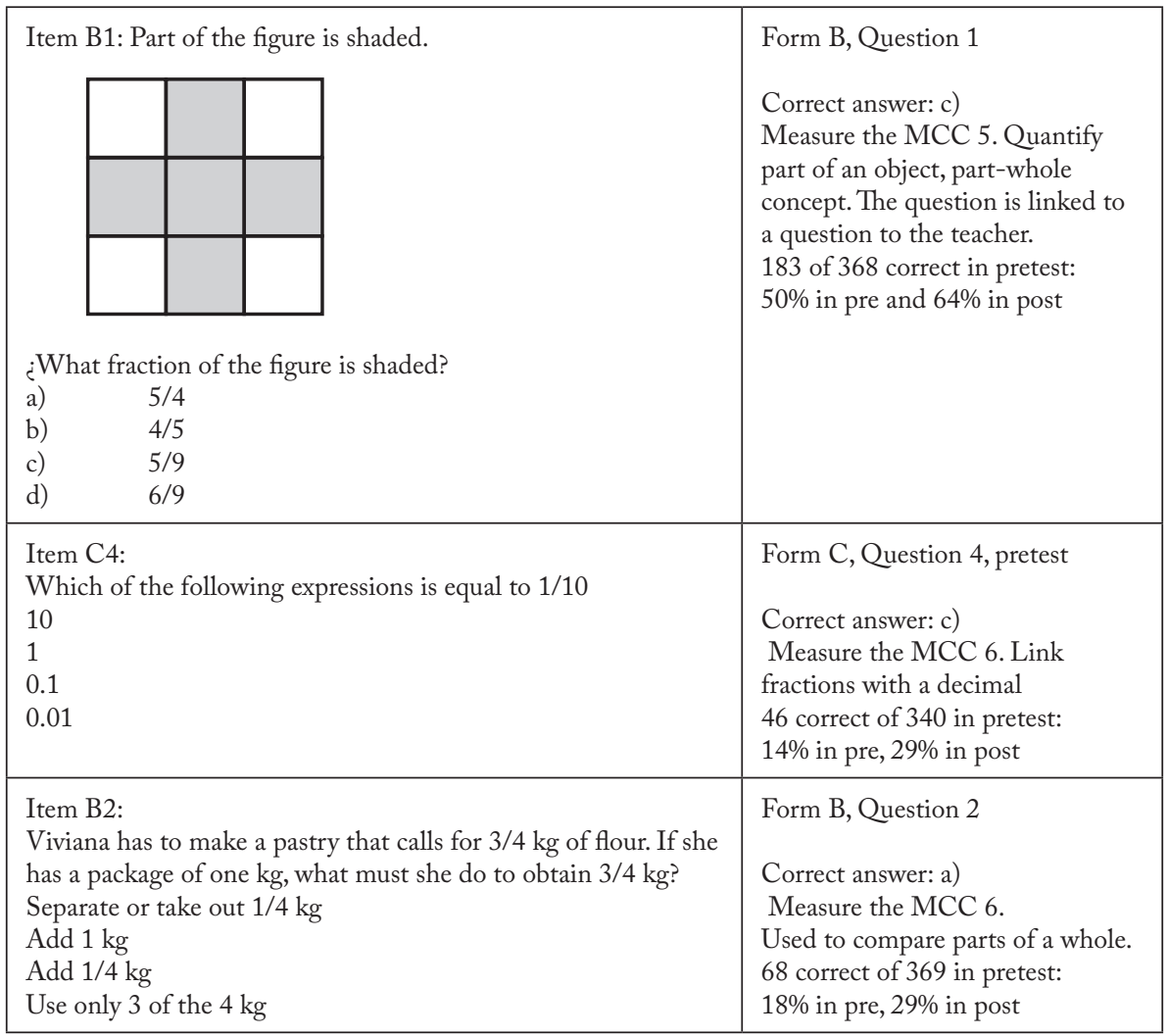




\section{APPENDIX C}

\section{Questions included only in the Achievement Test}

\begin{tabular}{|c|c|}
\hline $\begin{array}{l}\text { Item B7: } \\
\text { There are } 600 \text { balls in a box, and } 1 / 3 \text { of these balls are } \\
\text { red. How many red balls are there in the box? } \\
\text { a) } 600 \text { balls } \\
\text { b) } 1800 \text { balls } \\
\text { c) } 200 \text { balls } \\
\text { d) } 300 \text { balls }\end{array}$ & $\begin{array}{l}\text { Form B, Question } 7 \\
\text { Correct answer: c) } \\
\text { Measure the MCC } 5 \text {. } \\
\text { Fraction of a quantity, within the context of } \\
\text { problem solving. } \\
197 \text { correct of 508: } 39 \%\end{array}$ \\
\hline $\begin{array}{l}\text { Item A4: } \\
\text { I had a sum of money, of which I spent one third. If I } \\
\text { have } \$ 30 \text { left, how much was the initial sum? } \\
\$ 90 \\
\$ 60 \\
\$ 30 \\
\text { Another value }\end{array}$ & $\begin{array}{l}\text { Form A, Question } 4 \\
\text { Correct answer: d) } \\
\text { Measure the MCC } 5 \text {. } \\
\text { Controls the understanding of problem } \\
\text { solving, determines the fraction of a } \\
\text { measurement. } \\
93 \text { and } 96 \text { correct of } 528: 18 \%\end{array}$ \\
\hline
\end{tabular}

\section{APPENDIX D}

\section{Regression Analysis Graphs}

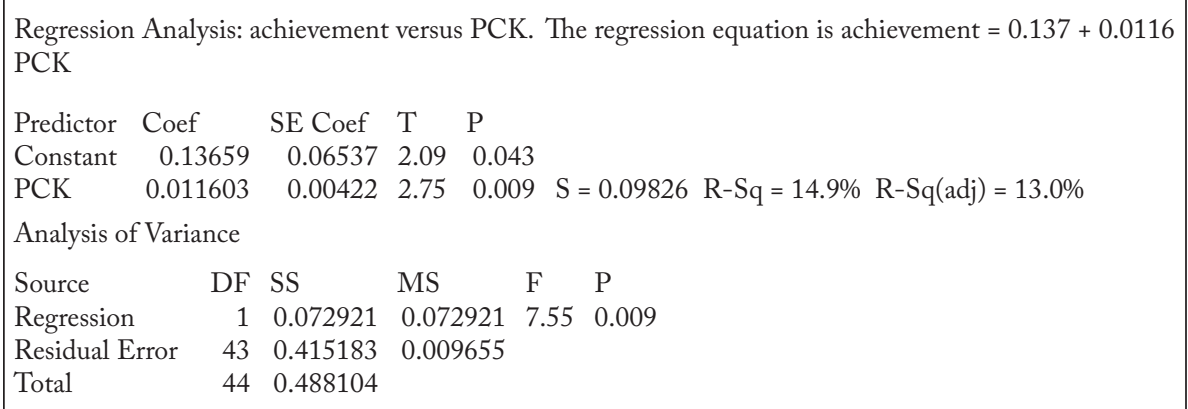

Figure 1 - Regression Analysis. Achievement versus PCK. 
Regression Analysis: Alumnos versus PCK; CK. The regression equation is achievement $=0.145+$ $0.00966 \mathrm{PCK}+0.00620 \mathrm{CK}$

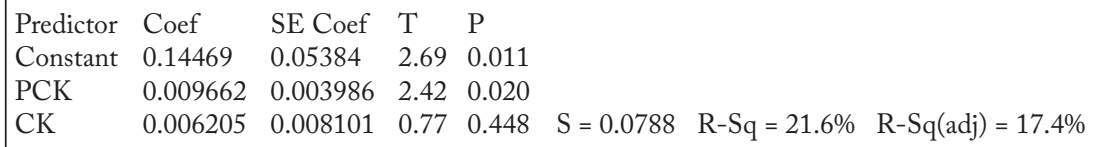

Figure 2 - Regression Analysis Achievement versus PCK y CK.

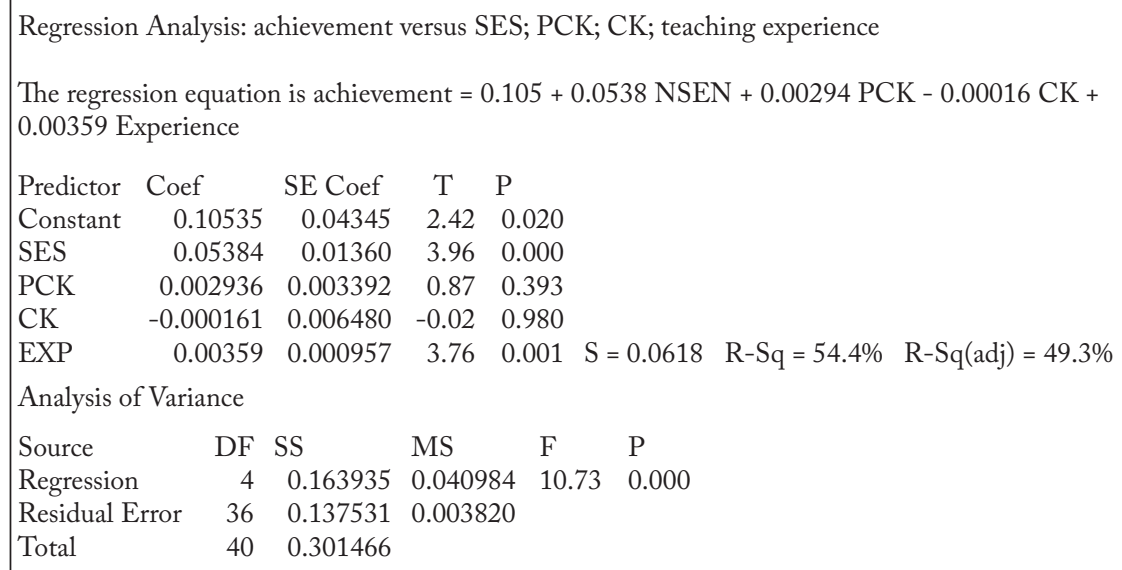

Figure 3 - Regression Analysis. Achievement versus SES; PCK; CK; teaching experience.
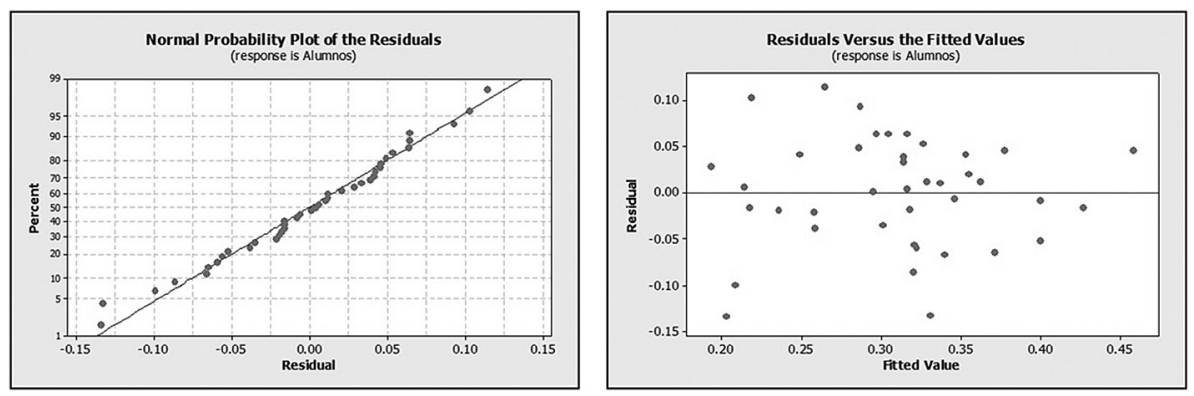

Figure 4 - Normality of the distribution of residuals and apparent lack of bias. 


\section{ABOUT THE AUTHORS}

Raimundo Olfos is $\mathrm{PhD}$ of education, University of Wales (Wales). Full professor at Pontificia Universidad Católica de Valparaíso (Chile).

E-mail: raimundo.olfos@ucv.cl

Tatiana Goldrine Godoy is doctor of educational psychology, Universidad Nacional Autónoma de México (México). Full professor at Pontificia Universidad Católica deValparaíso (Chile).

E-mail: tatiana.goldrine@ucv.cl

Soledad Estrella is doctor of didactic of matematic, Pontificia Universidad Católica de Valparaíso (Chile). Associated professor at the same university.

E-mail: soledad.estrella@ucv.cl

Recebido em março 2013

Aprovado em setembro de 2013 